\title{
Investigation of the Fiber Saturation Point of Tropical Brazilian Wood Species
}

Tiago H. Almeida, ${ }^{\mathrm{a}}$ Diego H. Almeida, ${ }^{\mathrm{b}}$ Vinicius B. M. Aquino, ${ }^{\mathrm{c}, *}$ Eduardo Chahud, ${ }^{\mathrm{d}}$ Roberto V. Pinheiro, ${ }^{\mathrm{e}}$ Luiz A. M. N. Branco, ${ }^{\mathrm{d}}$ João P. B. Almeida, ${ }^{\mathrm{f}}$ André L. Christoforo, ${ }^{\mathrm{f}}$ and Francisco A. R. Lahr ${ }^{\text {a }}$

The fiber saturation point (FSP) is an important parameter of wood material, related to dimensional stability and variations of mechanical performance. This paper investigated the FSP values of 15 tropical Brazilian wood species covering all strength classes of the Brazilian standard code. An additional goal was to estimate FSP value based on the wood's apparent density. The FSP values were determined by measuring the wood specimen dimensions during moisture content reduction from the saturated state. Wood densities at $0 \%$ and $12 \%$ moisture contents and basic density were determined according to the Brazilian standard code. The average FSP for all wood species was $21.6 \%$ moisture content. Among density values, good correlations were observed, and a multivariate regression model for FSP estimation based on wood densities presented a coefficient of determination equal to $13.07 \%$. There was no correlation between FSP and wood densities, suggesting that this parameter is almost constant regardless of the wood species.

Keywords: FSP; Regression model; Tropical wood

Contact information: a: Wood and Timber Structures Laboratory, Department of Structural Engineering, São Carlos School of Engineering of São Carlos, University of São Paulo (USP), São Carlos/SP, Brazil; b: Department of Civil Engineering, Federal University of Rondonia (UNIR), Porto Velho/RO, Brazil; c: Araguaia Engineering Institute, Federal University of Southern and Southeastern Pará (UNIFESSPA), Santana do Araguaia/PA, Brazil; d: Department of Civil Engineering, Federal University of Minas Gerais (UFMG), Belo Horizonte/MG, Brazil; e: Department of Civil Engineering, Mato Grosso State University (UNEMAT), Sinop/MT, Brazil; f: Department of Civil Engineering (DECiv), Federal University of São Carlos, São Carlos/SP, Brazil; *Corresponding author: aquino.vini@hotmail.com

\section{INTRODUCTION}

There are many wood species grown in Brazil (Ter Steege et al. 2016; Almeida et al. 2017), and many such species can be used as raw material for several sectors such as the furniture industry and civil construction (Calil Junior et al. 2003; Passarini and Hernández 2016). For better use of wood resources, it is important to characterize the physical and mechanical properties of wood (Almeida et al. 2016). The Brazilian standard code ABNT NBR 7190/1997 "Design of Timber Structures" (ABNT 1997) prescribes the procedures for both structural design and characterization of wood properties, as well as strength classes of wood based on the strength in compression parallel to the grain.

The fiber saturation point (FSP) is a well-established moisture content value (Babiak and Kúdela 1995; Jankowska and Kozakiewicz 2016; Zelinka et al. 2016). Two other indirect methods use experimental sorption isotherms and the Nelson sorption isotherm model. 
The FSP is the equilibrium moisture content at a given temperature when air relative humidity is equal to $1(100 \%)$. Below the FSP there is an increase in strength and stiffness of wood as it undergoes a drying process (Passarini et al. 2014). In addition, shrinkage of wood samples can be observed with this drying, which can cause dimensional stability problems (Galvão and Jankowsky 1985; Ye et al. 2006; Almeida et al. 2017; Tarmian 2017). Above this value of moisture content, there are no more dimensional variations (the wood sample has already achieved the green volume), and mechanical properties remain the same (Kollmann and Côte 1968; Murata et al. 2013; Zauer et al. 2014).

There is no consensus regarding the FSP value (Berry and Roderick 2005). Still, this parameter is important for better use of wood materials without variation in mechanical properties and higher dimensional stability. For Kollmann and Côté (1968) and Durlo and Marchiori (1992), among other authors, the average FSP is $28 \%$ moisture content. For Cisternas (1994), this parameter is $30 \%$ moisture content. The Brazilian standard code prescribes that the FSP value is about $25 \%$ moisture content. This parameter is related to the anatomical characteristics of wood (Kokutse et al. 2010).

Density is one of the most important physical properties of wood. This property can be easily determined, being the ratio between the weight and volume of a wood sample. Wood is a hygroscopic material and its density varies with the moisture content. Therefore it is necessary to specify the moisture content of the wood sample whose density has been determined (Almeida et al. 2016, 2017).

Based on that dependence of wood density and the moisture content of the sample, the basic density is beneficial for comparisons, because its value is always the same for the same sample, regardless of the moisture content of the sample. Basic density is the ratio between the weight of a dried sample and the green volume of the same sample, resulting in the smallest possible value for the density of this wood sample (Almeida et al. 2016; Jankowska and Kozakiewicz 2016).

This research investigated the fiber saturation point of tropical Brazilian wood species covering the five strength classes of the Brazilian standard code, providing more accurate results and trying to estimate this parameter based on the wood density using regression models.

\section{EXPERIMENTAL}

The five strength classes of the Brazilian standard code were considered here for investigating the fiber saturation point of tropical Brazilian wood species. Three wood species were considered for each strength class. Table 1 presents the 15 wood species considered in this study.

According to Annex B of the Brazilian standard code "Determination of wood properties for design of structures," (ABNT 1997), the following wood properties were determined: Densities at $0 \%$ and $12 \%$ moisture contents ( $d_{0}$ and $d_{12}$, respectively) and basic density $\left(d_{\text {bas }}\right)$. In addition, the FSP values were determined by measuring wood specimen dimensions during moisture content reduction from the saturated state (drying process). FSP is the moisture content value when the wood starts to shrink with the drying process. Figure 1 illustrates these measurements. Twelve repetitions were performed for each wood species considered totaling 180 determinations for each variable. 
Table 1. Tropical Brazilian Wood Species Considered - ABNT NBR 7190/1997

\begin{tabular}{|c|c|}
\hline Strength Class & Wood Species \\
\hline \multirow{4}{*}{ D20 } & Pachira quinata \\
\cline { 2 - 2 } & Cedrela sp. \\
\cline { 2 - 2 } & Erisma sp. \\
\hline \multirow{3}{*}{ D30 } & Cassia ferruginea \\
\cline { 2 - 2 } & Calophyllum sp. \\
\cline { 2 - 2 } & Ocotea odorifera \\
\hline \multirow{2}{*}{ D40 } & Vataieropsis araroba \\
\cline { 2 - 2 } & Goupia glabra \\
\cline { 2 - 2 } & Vatairea fusca \\
\hline \multirow{2}{*}{ D50 } & Qualea albiflora \\
\hline \multirow{2}{*}{ D60 } & Gossypiospermun praecox \\
\cline { 2 - 2 } & Bagassa guianensis \\
\cline { 2 - 2 } & Dinizia excelsa \\
\hline & Dipteryx sp. \\
\hline
\end{tabular}

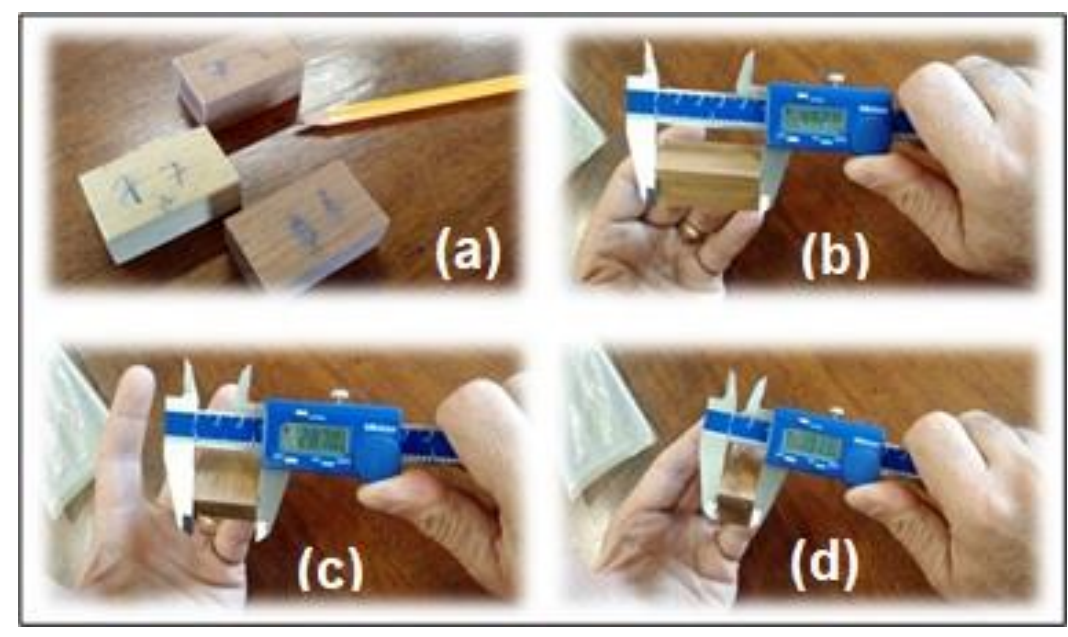

Fig. 1. Process of specimen measurement - Specimens (a); Length measurement (b); Width measurement (c); Thickness measurement (d)

Statistical analysis was performed using R-version 3.5.1 software (R Core Team, Vienna, Austria). A summary of results in general and for the five strength classes was made. Boxplots of dry density (density at $0 \%$ moisture content) and FSP moisture content were built for evaluating the behavior of these results for different strength classes. Scatter plots of variables were observed trying to determine a relation between wood densities and FSP (as well as the Pearson correlation matrix). Linear regression models between wood densities were determined, and a multivariate regression model was fitted for FSP estimation based on the wood densities.

Analyses of variance was carried out to test the representativeness of these models at a 5\% significance level. A P-value of less than 5\% shows acceptable model representativeness. The coefficient of determination $\mathrm{R}^{2}$ makes it possible to measure the interaction between dependent and independent variables. 


\section{RESULTS AND DISCUSSION}

By performing the wood densities determinations as well as the FSP measurement for the 15 wood species (covering the five classes), it was possible to summarize these results. Tables 2 to 7 presents summaries of results for all wood species in general, and for each strength class of the Brazilian standard code, respectively. The coefficient of variation is denoted by $\mathrm{CV}$.

Table 2. Summary of General Results

\begin{tabular}{|c|c|c|c|c|}
\hline General & $d_{12}\left(\mathrm{~g} / \mathrm{cm}^{3}\right)$ & $d_{0}\left(\mathrm{~g} / \mathrm{cm}^{3}\right)$ & $d_{\text {bas }}\left(\mathrm{g} / \mathrm{cm}^{3}\right)$ & FSP $(\%)$ \\
\hline Mean & 0.83 & 0.81 & 0.64 & 21.60 \\
\hline CV $(\%)$ & 23.12 & 24.70 & 23.50 & 16.70 \\
\hline Minimum & 0.44 & 0.40 & 0.37 & 15.68 \\
\hline Maximum & 1.25 & 1.24 & 0.98 & 36.04 \\
\hline Count & 180.00 & 180.00 & 180.00 & 180.00 \\
\hline
\end{tabular}

Table 3. Summary of D20 Strength Class Results

\begin{tabular}{|c|c|c|c|c|}
\hline D20 & $d_{12}\left(\mathrm{~g} / \mathrm{cm}^{3}\right)$ & $d_{0}\left(\mathrm{~g} / \mathrm{cm}^{3}\right)$ & $d_{\text {bas }}\left(\mathrm{g} / \mathrm{cm}^{3}\right)$ & FSP $(\%)$ \\
\hline Mean & 0.56 & 0.53 & 0.45 & 21.89 \\
\hline CV $(\%)$ & 15.93 & 16.43 & 13.06 & 19.30 \\
\hline Minimum & 0.44 & 0.40 & 0.37 & 15.68 \\
\hline Maximum & 0.74 & 0.69 & 0.58 & 36.00 \\
\hline Count & 36.00 & 36.00 & 36.00 & 36.00 \\
\hline
\end{tabular}

Table 4. Summary of D30 Strength Class Results

\begin{tabular}{|c|c|c|c|c|}
\hline D30 & $d_{12}\left(\mathrm{~g} / \mathrm{cm}^{3}\right)$ & $d_{0}\left(\mathrm{~g} / \mathrm{cm}^{3}\right)$ & $d_{\text {bas }}\left(\mathrm{g} / \mathrm{cm}^{3}\right)$ & FSP $(\%)$ \\
\hline Mean & 0.91 & 0.90 & 0.66 & 20.91 \\
\hline CV $(\%)$ & 14.62 & 15.65 & 7.88 & 13.64 \\
\hline Minimum & 0.74 & 0.70 & 0.58 & 15.90 \\
\hline Maximum & 1.15 & 1.15 & 0.78 & 25.87 \\
\hline Count & 36.00 & 36.00 & 36.00 & 36.00 \\
\hline
\end{tabular}

Table 5. Summary of D40 Strength Class Results

\begin{tabular}{|c|c|c|c|c|}
\hline D40 & $d_{12}\left(\mathrm{~g} / \mathrm{cm}^{3}\right)$ & $d_{0}\left(\mathrm{~g} / \mathrm{cm}^{3}\right)$ & $d_{\text {bas }}\left(\mathrm{g} / \mathrm{cm}^{3}\right)$ & FSP $(\%)$ \\
\hline Mean & 0.77 & 0.75 & 0.57 & 19.86 \\
\hline CV $(\%)$ & 10.15 & 11.12 & 15.06 & 15.08 \\
\hline Minimum & 0.60 & 0.56 & 0.41 & 15.94 \\
\hline Maximum & 0.88 & 0.87 & 0.75 & 27.51 \\
\hline Count & 36.00 & 36.00 & 36.00 & 36.00 \\
\hline
\end{tabular}

Table 6. Summary of D50 Strength Class Results

\begin{tabular}{|c|c|c|c|c|}
\hline D50 & $d_{12}\left(\mathrm{~g} / \mathrm{cm}^{3}\right)$ & $d_{0}\left(\mathrm{~g} / \mathrm{cm}^{3}\right)$ & $d_{\text {bas }}\left(\mathrm{g} / \mathrm{cm}^{3}\right)$ & FSP $(\%)$ \\
\hline Mean & 0.86 & 0.83 & 0.67 & 23.25 \\
\hline CV $(\%)$ & 10.27 & 11.46 & 8.24 & 16.88 \\
\hline Minimum & 0.69 & 0.66 & 0.56 & 16.03 \\
\hline Maximum & 1.06 & 1.06 & 0.77 & 36.04 \\
\hline Count & 36.00 & 36.00 & 36.00 & 36.00 \\
\hline
\end{tabular}


Table 7. Summary of D60 Strength Class Results

\begin{tabular}{|c|c|c|c|c|}
\hline D60 & $d_{12}\left(\mathrm{~g} / \mathrm{cm}^{3}\right)$ & $d_{0}\left(\mathrm{~g} / \mathrm{cm}^{3}\right)$ & $d_{\text {bas }}\left(\mathrm{g} / \mathrm{cm}^{3}\right)$ & $\mathrm{FSP}(\%)$ \\
\hline Mean & 1.04 & 1.03 & 0.86 & 22.10 \\
\hline CV $(\%)$ & 11.23 & 11.62 & 8.54 & 13.91 \\
\hline Minimum & 0.86 & 0.84 & 0.74 & 17.91 \\
\hline Maximum & 1.25 & 1.24 & 0.98 & 29.84 \\
\hline Count & 36.00 & 36.00 & 36.00 & 36.00 \\
\hline
\end{tabular}

The highest values for wood densities were found for a D60 wood species. On the other hand, the smallest values of wood densities resulted from a D20 wood species. The highest FSP was $36.04 \%$ for a sample of the D50 wood species, and the lowest FSP value was $15.68 \%$ for an example of the D20 wood species.

In Figs. 2 and 3, boxplots of FSP and dry density values are shown for all strength classes. The horizontal lines represent the overall average value (covering all fifteen wood species), and the average value by strength class is represented by solid points (red and blue for FSP and dry density, respectively).

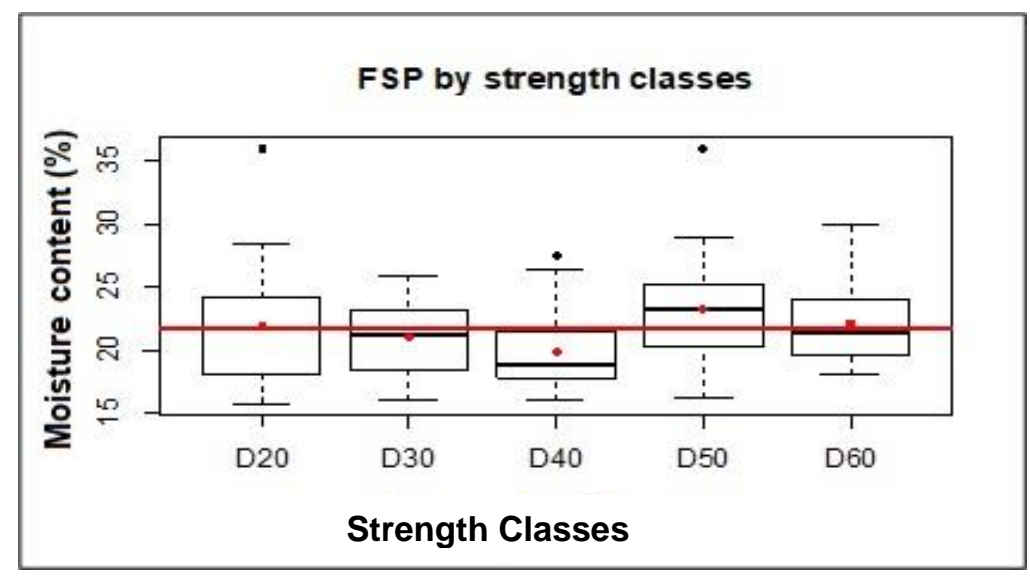

Fig. 2. Boxplots of FSP results for each strength class

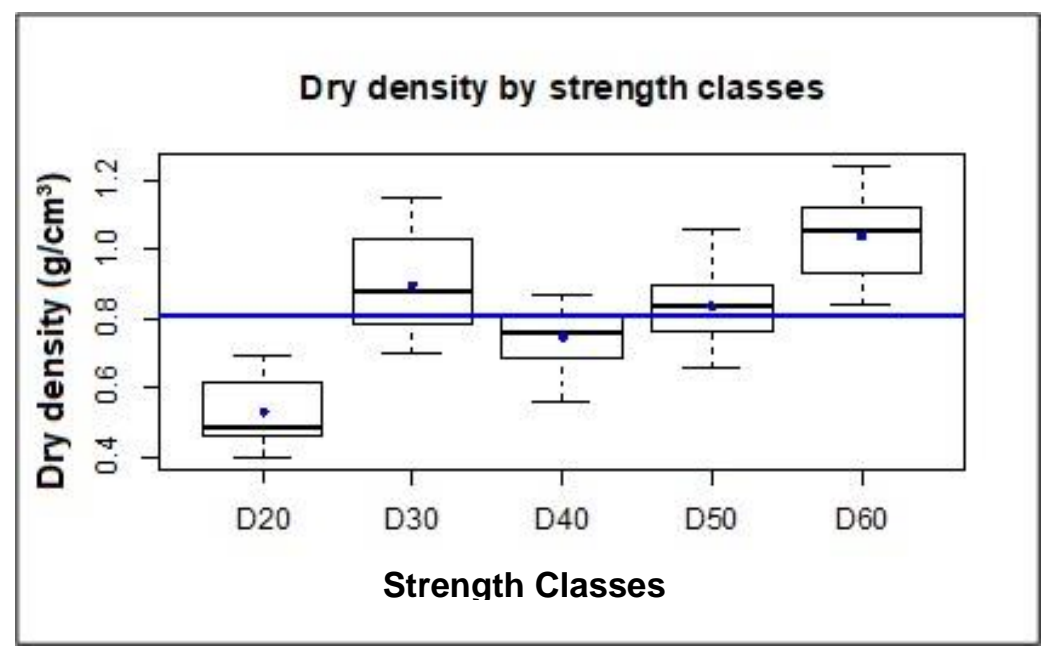

Fig. 3. Boxplots of Dry density values for each strength class 
Figures 2 and 3 make it possible to observe a tendency of increase of wood density with the increasing of the strength class (that is based on the strength in compression parallel to grain), but FSP values seem not to change so much with strength class variation. It is important to highlight that the D30 wood species presented high-density values (Fig. 3 ), which seems to be related to anatomical characteristics of wood (grain direction, for example).

Scatterplots and Pearson correlation were carried out to investigate the interaction among the variables. Figure 4 shows the scatterplots for densities and FSP in pairs, and Table 8 presents the Pearson correlation coefficients for each pair that has been plotted.

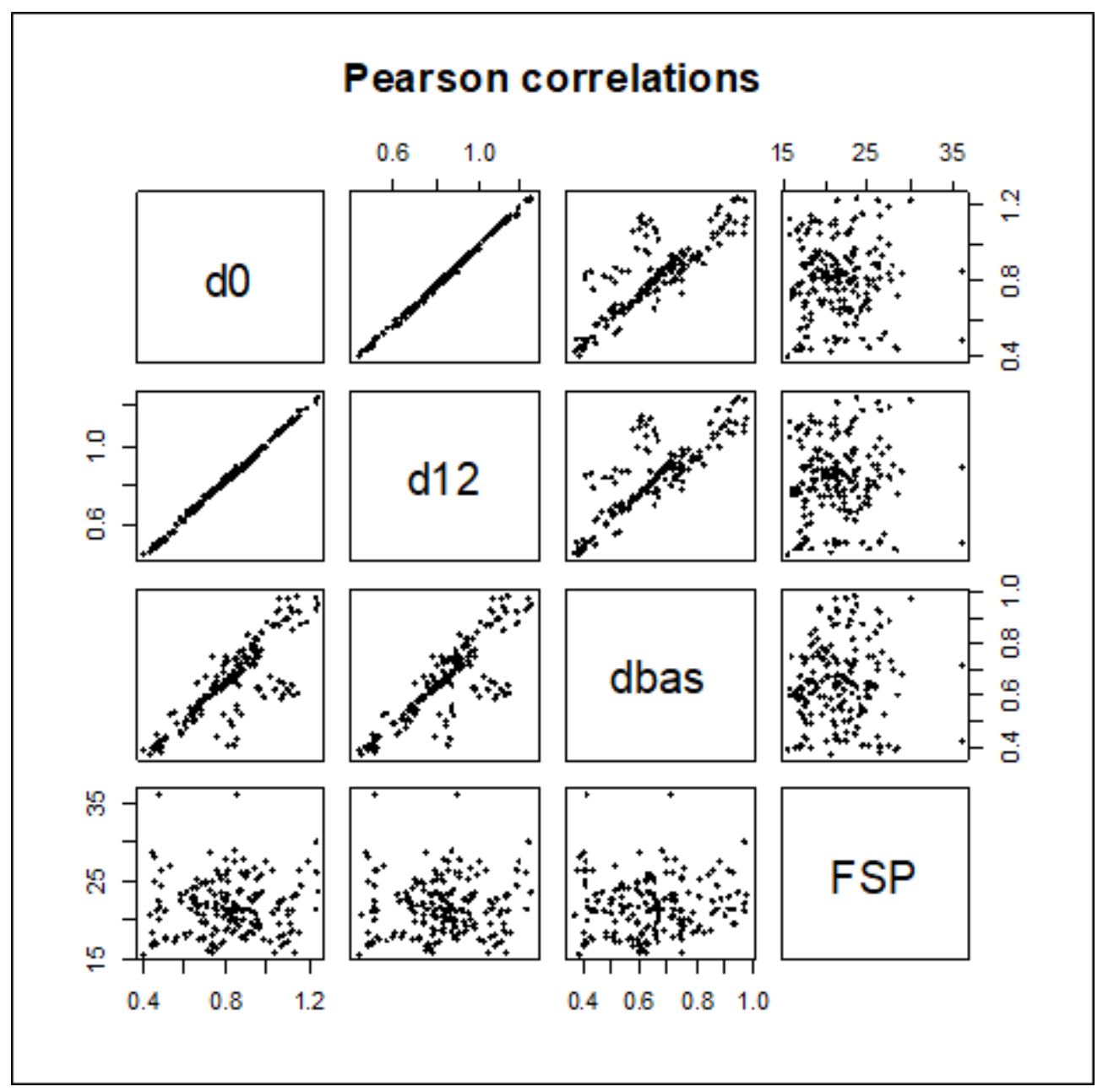

Fig. 4. Scatterplots of dry density values for each strength class

Table 8. Matrix of Pearson Correlation

\begin{tabular}{|l|l|l|l|l|}
\hline Variables & $\boldsymbol{d}_{\mathbf{0}}$ & $\boldsymbol{d}_{\mathbf{1 2}}$ & $\boldsymbol{d}_{\text {bas }}$ & FSP \\
\hline$d_{0}$ & 1 & 0.9986 & 0.8347 & 0.0155 \\
\hline$d_{12}$ & 0.9986 & 1 & 0.8354 & 0.0245 \\
\hline$d_{\text {bas }}$ & 0.8347 & 0.8354 & 1 & 0.0862 \\
\hline FSP & 0.0155 & 0.0245 & 0.0862 & 1 \\
\hline
\end{tabular}

Based on Fig. 4 and the Pearson correlation coefficients shown in Table 8, it is possible to observe that there was no correlation between FSP values and wood densities 
( $\mathrm{r} \leq 0.0862$ ). On the other hand, a high correlation between wood density values was observed, and Table 9 presents linear regression models fitted by the ordinary least square method and tested by Analysis of Variance (ANOVA).

Table 9. Matrix of Pearson Correlation

\begin{tabular}{|l|l|l|l|l|l|}
\hline Independent & Dependent & Intercept & Slope & $\mathbf{R}^{2}$ & P-value \\
\hline$d_{12}$ & $d_{0}$ & -0.0539 & 1.0396 & 0.9971 & 0.0000 \\
\hline$d_{\text {bas }}$ & $d_{12}$ & 0.14769 & 1.06224 & 0.6962 & 0.0000 \\
\hline$d_{\text {bas }}$ & $d_{0}$ & 0.09916 & 1.10499 & 0.6951 & 0.0000 \\
\hline
\end{tabular}

As shown in Table 9, all three linear models were significant (P-value $<0.05)$. The linear regression model for $d_{12}$ and $d_{0}$ variables presented the highest $\mathrm{P}$-value being $\mathrm{R}^{2}$ $99.71 \%$. The lowest coefficient of determination was $69.51 \%$ for $d_{\text {bas }}$ and $d_{0}$ variables.

A multivariate regression model was performed to find a relation between wood densities and FSP, making it easier for its determination. This model had the following independent variables: $d_{12}, d_{0}, d_{\text {bas }}, d_{12}, d_{0}, d_{12} \times d_{\text {bas }}, d_{0} \times d_{\text {bas }}$, and $d_{12} \times d_{0} \times d_{\text {bas. }}$ Table 10 shows the estimated coefficients for this model.

Table 10. Multivariate Regression Model for FSP Determination Based on Wood Density Values

\begin{tabular}{|c|c|c|c|c|}
\hline Coefficients & Estimated value & P-value & Model's P-value & $\mathrm{R}^{2}$ (Adj.) \\
\hline Intercept & 26.7400 & 0.1196 & & \\
\hline$d_{12}$ & -139.4300 & 0.2205 & & \\
\hline$d_{0}$ & 206.4800 & 0.0644 & & \\
\hline$d_{\text {bas }}$ & -79.2900 & 0.0576 & & \multirow{2}{*}{0.0000} \\
\hline$d_{12} \times d_{0}$ & -75.9300 & $\underline{0.0023}$ & & \\
\hline$d_{12} \times d_{\text {bas }}$ & 401.6100 & $\underline{0.0301}$ & & \\
\hline$d_{0} \times d_{\text {bas }}$ & -349.9300 & $\underline{0.0424}$ & & \\
\hline$d_{12} \times d_{0} \times d_{\text {bas }}$ & 30.6200 & 0.4365 & & \\
\hline
\end{tabular}

ANOVA at a 5\% significance level was performed for investigating the representativeness of the multivariate regression model resulting P-value less than 0.05 , which leads us to accept the model representativeness. But, on the other hand, the coefficient of determination was $13.07 \%$, and only $d_{12} \times d_{0}, d_{12} \times d_{\text {bas }}$, and $d_{0} \times d_{\text {bas }}$ were the significative independent variables of the model (underlined P-values).

The results of the Pearson correlation matrix and the multivariate regression model suggest that the FSP does not depend on the wood density, being a constant parameter related to the anatomical characteristics of wood. The average value and the coefficient of variation of FSP for the fifteen tropical Brazilian wood species considered were $21.6 \%$ and $16.70 \%$, respectively, being lower than the moisture content value provided for the literature.

\section{CONCLUSIONS}

1. The values of fiber saturation point do not vary with different strength classes of wood in compliance with the Brazilian standard code; In addition, the average fiber saturation point for fifteen tropical Brazilian wood species was at $21.6 \%$ moisture. 
2. There is no correlation between fiber saturation point and wood densities; the highest coefficient of correlation was 0.0862 for FSP $\sim \mathrm{d}_{\text {bas }}$ (fiber saturation point as a function of basic density).

3. The investigation of the Pearson correlation between densities at $0 \%$ and $12 \%$ moisture and basic density provided coefficients of correlation greater than 0.80 , the highest value being between densities at $0 \%$ and $12 \%$ moisture.

4. Linear regression models among wood densities were significant, resulting in coefficients of determination equal to $99.71 \%, 69.62 \%$, and $69.51 \%$, for $d_{0} \sim d_{12}, d_{12} \sim$ $d_{\text {bas, }}$ and $d_{0} \sim d_{\text {bas }}$, respectively.

5. The multivariate regression model for FSP estimation by the wood densities was significant; the coefficient of determination was equal to $13.07 \%$, but only the independent variables $d_{12} \times d_{0}, d_{12} \times d_{\text {bas }}$, and $d_{0} \times d_{\text {bas }}$ were significant.

6. The FSP is not well correlated with wood densities, as well as the strength classes of wood, leading us to conclude that this parameter is almost constant regardless of the physical properties of wood.

\section{ACKNOWLEDGMENTS}

Authors thank CAPES for the financial support (this study was financed by the Coordenação de Aperfeiçoamento de Pessoal de Nível Superior - Brasil (CAPES) - Finance Code 001), Laboratory of Wood and Timber Structures (LaMEM) of the Engineering of Structures Department (SET) of the Engineering School of São Carlos (EESC) - University of São Paulo (USP).

\section{REFERENCES CITED}

ABNT NBR 7190 (1997). "Projeto de estruturas de madeira," Associação Brasileira de Normas Técnicas, Rio de Janeiro, Brazil.

Almeida, T. H., Almeida, D. H., de Araujo, V. A., Silva, S. A. M., Christoforo, A. L., and Lahr, F. A. R. (2017). "Density as estimator of dimensional stability quantities of Brazilian tropical woods," BioResources 12(3), 6579-6590. DOI: 10.15376/biores.12.3.6579-6590

Almeida, T. H., Almeida, D. H., Christoforo, A. L., Chahud, E., Branco, L. A. M. N., and Lahr, F. A. R. (2016). "Density as estimator of strength in compression parallel to the grain in wood," International Journal of Materials Engineering 6(3), 67-71. DOI: 10.5923/j.ijme.20160603.01

Babiak, M., and Kúdela, J. (1995). "A contribution to the definition of the fiber saturation point," Wood Science and Technology 29(3), 217-226. DOI: 10.1007/BF00204589

Berry, S. L., and Roderick, M. L. (2005). "Plant-water relations and the fibre saturation point," The New Phytologist 168(1), 25-37. DOI: 10.1111/j.1469-8137.2005.01528.x

Calil Junior, C., Lahr, F. A. R., and Dias, A. A. (2003). Dimensionamento de Elementos Estruturais de Madeira, Editora Manole, Barueri, São Paulo, Brazil.

Cisternas, P. A. (1994). "Conversion de densidades de la madera," Ciencia e Investigación Forestal 8(2), 300-315. 
Durlo, M. A., and Marchiori, J. N. C. (1992). Tecnologia da Madeira: Retratibilidade, Série Técnica 10, 33.

Galvão, A. P. M., and Jankowsky, I. P. (1985). Secagem Racional da Madeira, Nobel, São Paulo, Brazil.

Jankowska, A., and Kozakiewicz, P. (2016). "Determination of fibre saturation point of selected tropical wood species using different methods," Drewno 59(197), 89-97. DOI: 10.12841/wood.1644-3985.C07.12

Kokutse, A. D., Brancheriau, L., and Chaix, G. (2010). "Rapid prediction of shrinkage and fibre saturation point on teak (Tectona grandis) wood based on near-infrared spectroscopy," Annals of Forest Science 67(4), 403. DOI: 10.1051/forest/2009123

Kollmann, F. F. P., and Côte, W. A. (1968). Principles of Wood Science and Technology, Springer-Verlag, Berlin, Germany.

Murata, K., Watanabe, Y., and Nakano, T. (2013). "Effect of thermal treatment on fracture properties and adsorption properties of spruce wood," Materials 6(9), 41864197. DOI: $10.3390 / \mathrm{ma6094186}$

Passarini, L., and Hernández, R. E. (2016). "Effect of the desorption rate on the dimensional changes of Eucalyptus saligna wood," Wood Science and Technology 50(5), 941-951. DOI: 10.1007/s00226-016-0839-8

Passarini, L., Malveau, C., and Hernández, R. E. (2014). "Water state study of wood structure of four hardwoods below fiber saturation point with nuclear magnetic resonance," Wood and Fiber Science 46(4), 480-488.

Ter Steege, H., Vaessen, R. W., Cárdenas-López, D., Sabatier, D., Antonelli, A., de Oliveira, S. M., Pitman, N. C. A., Jørgensen, P. M., and Salomão, R. P. (2016). "The discovery of the Amazonian tree flora with an updated checklist of all known tree taxa," Scientific Reports 6, 29549. DOI: 10.1038/srep29549

Tarmian, A. (2017). "Measurement of fiber saturation point of wood using differential scanning calorimetry: Measurement fundamentals and experimental results," Iranian Journal of Wood and Paper Industries 7(4), 615-623.

Ye, X., Wang, S., Ruan, R., Qi, J., Womac, A. R., and Doona, C. J. (2006). "Water mobility and mold susceptibility of engineered wood products," Transactions of the $A S A B E, 49(4), 1159-1165$. DOI: 10.13031/2013.21733

Zauer, M., Kretzschmar, J., Großmann, L., Pfriem, A., and Wagenführ, A. (2014). "Analysis of the pore-size distribution and fiber saturation point of native and thermally modified wood using differential scanning calorimetry," Wood Science and Technology 48(1), 177-193. DOI: 10.1007/s00226-013-0597-9

Zelinka, S. L., Glass, S. V., Jakes, J. E., and Stone, D. S. (2016). “A solution thermodynamics definition of the fiber saturation point and the derivation of a woodwater phase (state) diagram," Wood Science and Technology 50(3), 443-462. DOI: 10.1007/s00226-015-0788-7

Article submitted: March 4, 2020; Peer review completed: May 9, 2020; Revised version received and accepted: May 19, 2020; Published: May 22, 2020.

DOI: $10.15376 /$ biores.15.3.5379-5387 